\title{
Clinical and Neurophysiological Pattern of Guillain-Barré Syndrome in Kuwait
}

\author{
Venkatesan Nagarajan Asmahan Al-Shubaili \\ Department of Neurology, Ibn Sina Hospital, Kuwait
}

\author{
Key Words \\ Guillain-Barré syndrome · Acute inflammatory \\ polyradiculoneuropathy - Acute idiopathic \\ demyelinating polyradiculoneuropathy - Acute flaccid \\ paralysis $\cdot$ Middle East $\cdot$ Mediterranean $\cdot$ Kuwait
}

\begin{abstract}
Objective: To study the clinical and neurophysiological pattern of Guillain-Barré syndrome (GBS) in Kuwait. Materials and Methods: The clinical records of consecutive GBS patients admitted to Ibn Sina Hospital, Kuwait, during a 7-year period between 1997 and 2003 were analyzed. Results: Of the 41 cases, $77 \%$ were male. The majority of the cases presented during the winter months and a preceding infection was reported in two thirds of them. Proximal lower limb (LL) weakness was the predominant clinical presentation. Nerve conduction studies (NCS) demonstrated a demyelinating pattern in 70\%, an axonal pattern in $15 \%$, mixed type in $5 \%$ and no abnormality in the remaining $5 \%$. The majority of the patients $(73 \%)$ improved with one course of intravenous immunoglobulin (IV IG). Mean recovery time (MRT) was 4.4 weeks. Delayed recovery (MRT $\geq 6$ weeks) was noted in patients with predominant distal weakness in the LL (MRT 7.8 weeks; $p=0.001$ ), proximal weakness in the upper limb (UL) (MRT 6 weeks; $p=0.005$ ), autonomic disturbance (MRT 6.5 weeks; $p=0.05$ ), and axonal type GBS (MRT 6 weeks; $p=0.001$ ). Conclusion: The presence of predominant distal weakness in LL, proximal weak-
\end{abstract}

ness in $\mathrm{UL}$, autonomic disturbance and axonal pattern in NCS predict a poor outcome. Hence we recommend early immunomodulatory therapy in patients presenting with these features.

Copyright (C) 2006 S. Karger AG, Basel

\section{Introduction}

Guillain-Barré syndrome (GBS) is an autoimmune polyradiculoneuropathy, the most common cause of acute flaccid paralysis in all age groups after the polio era. GBS is not a disease with variations but a group of syndromes with distinctive subtypes depending upon the site of the immune attack. The major subtypes are acute idiopathic demyelinating polyradiculoneuropathy if the primary target of attack is the myelin sheath, acute motor axonal neuropathy (AMAN) if it involves motor axons at the internodal area, and acute motor sensory axonal neuropathy (AMSAN) if both motor and sensory axons are affected [1]. The triad of ataxia, areflexia and ophthalmoplegia, known as Miller Fisher syndrome (MFS), is due to predominant (demyelinating) attack on extraocular motor nerves and proprioceptive sensory fibers. The incidence of these 4 major subtypes differs from region to region with acute idiopathic demyelinating polyradiculoneuropathy predominating in the West, AMAN in China, and MFS in Japan and Taiwan [1]. All of them are characterized by acute atonic areflexic motor weakness with albumino-cytological dissociation. With the ex- 
ception of MFS the other subtypes cannot be easily distinguished by clinical features but can be differentiated by electrophysiological characteristics [1]. The natural course of the disease is the progression of motor weakness (up to 4 weeks) that reaches the maximum deficit (nadir) and remains at nadir for several weeks before improvement starts [2]. Early introduction (within 2 weeks of onset) of immunomodulatory therapy can arrest the progression and hasten the recovery. There are no proper clinical studies about adult GBS in the Gulf region. This study was carried out to analyze the clinical and neurophysiological pattern of GBS in Kuwait.

\section{Materials and Methods}

Ibn Sina Hospital is the only tertiary neurological care center in Kuwait that receives most of the GBS cases. The clinical records of all the GBS patients admitted to the hospital between January 1997 and December 2003 were analyzed. The patients who did not satisfy the Asbury and Cornblath [3] criteria were excluded from the study. The functional status of the patients was assessed using a modified objective scale of Miller published by Ammache et al. [4]. After clinical assessment, all the patients underwent lumbar puncture (LP) and nerve conduction studies (NCS) using standard techniques [5]. The Italian Guillain-Barré Study Group electrodiagnostic criteria were used to classify the NCS as demyelinating, axonal or mixed type [6]. Immediately after diagnosis, every patient was given intravenous immunoglobulin (IV IG) $0.4 \mathrm{~g} / \mathrm{kg}$ body weight for 5 days if the functional grading was more than 2 on Miller's scale. If the weakness persisted over 10 days after the first course of IV IG, a second course of IV IG was given. If the functional grade deteriorated, the patient was subjected to plasma exchange (PE). The recovery time was calculated as the time the patients began to improve by one grade on Miller's scale from nadir. Since the deterioration or recovery may not be so dramatic over days, we used weeks as a scale of measure. From the mean recovery time (MRT), faster (MRT - 1 SD) and slower (MRT + $1 \mathrm{SD}$ ) recoveries were defined. The significance of MRT in any subset was taken into consideration if it involved more than $10 \%$ of the study population and was analyzed using Student's t test.

\section{Results}

Forty-one (41) patients satisfied the diagnostic criteria; 30 males and 11 females with a male to female ratio of 2.7:1. The mean age was $41 \pm 15.9$ years (range $16-$ 72 years). The distributions of age, sex and nationality are given in table 1. Most of the admissions (59\%) were during the winter months of November to March. Twenty-seven (66\%) patients gave history of preceding illness of which respiratory illness (44\%) was the commonest. Of $7(17 \%)$ patients with gastro-intestinal problems, 6 had
Table 1. Age, sex and nationality distribution of patients with GBS and their MRT

\begin{tabular}{|c|c|c|c|c|c|c|c|}
\hline \multirow[t]{2}{*}{ Age } & \multicolumn{2}{|c|}{$\begin{array}{l}\text { Kuwaiti } \\
\mathrm{n}=21\end{array}$} & \multicolumn{2}{|c|}{$\begin{array}{l}\text { Non-Kuwaiti } \\
\mathrm{n}=20\end{array}$} & \multicolumn{2}{|c|}{$\begin{array}{l}\text { Total } \\
\mathrm{n}=41\end{array}$} & \multirow{2}{*}{$\begin{array}{l}\text { MRT } \\
\mathrm{n}=41 \\
\text { weeks }\end{array}$} \\
\hline & $\mathrm{M}$ & $\mathrm{F}$ & $\mathrm{M}$ & $\mathrm{F}$ & $\mathrm{n}$ & $\%$ & \\
\hline$<20$ & 2 & - & 1 & - & 3 & 7 & 3.3 \\
\hline $20-29$ & 1 & 3 & 3 & - & 7 & 17 & 4.6 \\
\hline $30-39$ & 3 & - & 5 & 2 & 10 & 25 & 4.5 \\
\hline 40-49 & 1 & 2 & 6 & 1 & 10 & 25 & 3.9 \\
\hline $50-59$ & - & 1 & 2 & 0 & 3 & 7 & 6.0 \\
\hline $60-69$ & 3 & 2 & - & - & 5 & 12 & 5.4 \\
\hline$>70$ & 3 & - & - & - & 3 & 7 & 3.3 \\
\hline Total & 13 & 8 & 17 & 3 & 41 & 100 & 4.4 \\
\hline
\end{tabular}

diarrhea and 1 nonspecific abdominal pain. No prior illness was reported by $14(34 \%)$ patients. The patients were admitted within 1 day to a maximum of 31 days after the onset of the illness with an average of 8.3 days.

\section{Clinical Features}

Of the 41 patients, three (7\%) had MFS. With the exception of 1 MFS patient, all the others had motor weakness. In most of them, the weakness started in the lower limbs (LL), then ascended to involve the upper limbs (UL). Combined involvement of both proximal and distal muscle was predominant in the UL, whereas in the LL predominant proximal muscle weakness was noted. The deep tendon reflexes were absent in 38 (93\%) patients, sluggish in $2(5 \%)$ and present in $1(2 \%)$ throughout the course of the illness. There were no sensory complaints in $18(44 \%)$ patients at presentation. The patterns of sensory disturbance and motor weakness are given in table 2 . The other clinical features like cranial nerve affection, autonomic disturbance and respiratory failure are summarized in table 3. Ophthalmoplegia occurred in all 3 MFS and in 1 GBS patient. Facial weakness was the commonest cranial nerve affection occurring in more than half of the patients. Bulbar weakness was noted in 6 patients (15\%) and 5 of them developed autonomic disturbance and respiratory failure leading to prolonged ventilatory support and delayed recovery. In addition to these 5 patients, another 2 needed ventilatory support for a few hours and did not have either autonomic disturbance or bulbar palsy. Of the 7 patients requiring ventilatory support, 3 were Kuwaitis ( 2 male and 1 female) and 4 were of other nationalities ( 3 male and 1 female) and all of them of different ages. The commonest autonomic 
Table 2. Patterns of motor weakness and sensory disturbances and the respective MRT in patients with GBS
Table 3. Cranial nerve affection, autonomic disturbance and breathing pattern of GBS patients and the respective MRT

\begin{tabular}{llrrr}
\hline \multirow{2}{*}{ Clinical features } & Signs/pattern & \multicolumn{2}{c}{ Patients } & \multirow{2}{*}{$\begin{array}{c}\text { MRT } \\
\text { weeks }\end{array}$} \\
\cline { 3 - 4 } & & $\mathrm{n}$ & $\%$ & \\
\hline \multirow{2}{*}{ Evolution of motor weakness } & & 40 & 98 & 4.5 \\
& Ascending & 37 & 91 & 4.5 \\
Weakness in UL & Descending & 3 & 7 & 4.3 \\
& & 40 & 98 & 4.5 \\
Weakness in LL & Proximal > distal & 7 & 17 & 6.0 \\
& Distal > proximal & 10 & 25 & 4.5 \\
& Distal = proximal & 23 & 56 & 4.0 \\
& & 40 & 98 & 4.5 \\
Sensory loss & Proximal > distal & 37 & 88 & 4.1 \\
& Distal $\geq$ proximal & 4 & 10 & 7.8 \\
& & 23 & 56 & 4.7 \\
& Paresthesia only & 3 & 7 & 3.7 \\
& Joint position sense only & 5 & 12 & 4.2 \\
& Glove and stocking only & 4 & 10 & 5.8 \\
& All 3 together & 2 & 5 & 6.5 \\
& Any combination of above & 9 & 22 & 4.4 \\
\hline
\end{tabular}

\begin{tabular}{llrrr}
\hline \multirow{2}{*}{$\begin{array}{l}\text { Clinical features } \\
\text { Signs/pattern }\end{array}$} & \multicolumn{2}{c}{ Patients } & \multirow{2}{*}{$\begin{array}{c}\text { MRT } \\
\text { weeks }\end{array}$} \\
\cline { 3 - 4 } & & $\mathrm{n}$ & $\%$ & \\
\hline \multirow{2}{*}{ Cranial nerve involvement } & Ophthalmoplegia & 4 & 10 & 3.8 \\
& Unilateral facial involvement & 1 & 2 & 5.0 \\
& Bilateral facial involvement & 20 & 49 & 4.3 \\
& No facial involvement & 20 & 49 & 4.6 \\
& Bulbar palsy & 6 & 15 & 5.5 \\
Breathing pattern & Ventilatory support & 7 & 17 & 6.1 \\
Autonomic disturbances & No ventilatory support & 34 & 83 & 4.1 \\
& & 9 & 22 & 5.6 \\
& Labile hypertension alone & 3 & 8 & 4.6 \\
& Retention of urine alone & 1 & 2 & 5.0 \\
& Both together & 5 & 12 & 6.2 \\
\hline
\end{tabular}

disturbance was a combination of labile hypertension and urinary retention. One patient had tachycardia and none developed gastric disturbance or pulmonary edema.

\section{Laboratory Features}

Most of the patients had undergone LP. Three patients refused the test. In 11 of 12 patients, in whom the CSF protein was normal, the study was performed within 2 weeks of onset of the illness. The albumino-cytological dissociation was noted in $68 \%$, with CSF protein elevation in 26 patients (table 4); mean value 1.215 and highest value $6.149 \mathrm{~g} / \mathrm{l}$; the mean CSF cell count was $<1$ cell/ $\mu l$. Among MFS patients 1 had elevated CSF protein and demyelinating type NCS and the other had normal CSF protein and NCS.

Forty of 41 patients had undergone NCS. The most commonly encountered neurophysiological abnormalities were absent or prolonged $\mathrm{F}$ wave: $90 \%$, prolonged distal latency: $80 \%$, absent $\mathrm{H}$ reflex: $76 \%$, delayed nerve conduction velocity: $73 \%$, partial or complete conduction block: 63\%, abnormal blink reflex: 60\%, reduced compound muscle action potentials (CMAP): $38 \%$ and abnormal sensory nerve action potentials (SNAP): $28 \%$. Demyelination was the predominant type in the neurophysiological work-up followed by axonal type (table 4). Of the 6 patients with axonal forms, 3 had either absent or low 
Table 4. Laboratory features of the disease with respective MRT

\begin{tabular}{|c|c|c|c|c|}
\hline \multirow[t]{2}{*}{ Investigation } & \multirow[t]{2}{*}{ Features } & \multicolumn{2}{|c|}{ Patients } & \multirow{2}{*}{$\begin{array}{l}\text { MRT } \\
\text { weeks }\end{array}$} \\
\hline & & $\mathrm{n}$ & $\%$ & \\
\hline \multirow[t]{7}{*}{ CSF } & No cells & 29 & 70 & 4.5 \\
\hline & Less than 10 cells $/ \mu 1$ & 9 & 22 & 4.0 \\
\hline & Protein normal $(<0.45 \mathrm{~g})$ & 12 & 29 & 4.4 \\
\hline & Protein $0.45-1 \mathrm{~g}$ & 9 & 24 & 4.1 \\
\hline & $1-2 \mathrm{~g}$ & 10 & 26 & 4.1 \\
\hline & $2-3 \mathrm{~g}$ & 5 & 13 & 5.0 \\
\hline & $>3 \mathrm{~g}$ & 2 & 4 & 5.5 \\
\hline \multirow{5}{*}{$\begin{array}{l}\text { Nerve } \\
\text { conduction }\end{array}$} & Demyelination type & 28 & 68 & 4.4 \\
\hline & Axonal type & 6 & 15 & 6.0 \\
\hline & Mixed type & 2 & 5 & 3.5 \\
\hline & $\mathrm{H}$ reflex abnormality alone & 2 & 5 & 3.5 \\
\hline & Normal & 2 & 5 & 3.0 \\
\hline
\end{tabular}

SNAP, which characterizes the AMSAN variant and the other 3 had normal SNAP, typical for the AMAN type.

\section{Treatment and Outcome}

Thirty-nine of 41 patients received IV IG. One patient was admitted and given IV IG on the day of illness onset; for two patients (5\%), IV IG administration was delayed up to the 12th and 13th day of admission because of the atypical progression of their illness. Of the 6 patients with delayed admission, 3 received IV IG in the 3rd week and the other 3 in the 4th week after the onset of the neuritic symptoms. Recovery was accordingly delayed in these patients.

Of the 39 patients, $30(77 \%)$ improved with one course of IV IG, $4(10 \%)$ required a second course after an interval of 10 days and $5(13 \%)$ deteriorated rapidly and required PE. Upon initiation of the treatment, disease progression was arrested, the duration of the plateau phase was shortened and the recovery started in most of the patients (table 5). In 9 patients, the progression continued up to 4 weeks, and 4 of them required ventilatory support and PE. Two (5\%) patients, in whom the plateau phase was prolonged for more than 2 weeks, showed a delayed recovery. In $2(5 \%)$ patients there was no plateau phase and they recovered early. No deterioration was noted, once the improvement started from nadir. No acute relapses (within 2-3 weeks of treatment) were noted in our patients.

The MRT was $4.4 \pm 1.6$ weeks and fast and slow recovery times were 2.8 and 6 weeks, respectively. The MRT was 4.3 weeks for males and 4.7 weeks for females.
Table 5. Treatment and outcome of the disease with respective MRT

\begin{tabular}{|c|c|c|c|c|}
\hline \multirow[t]{2}{*}{ Outcome } & \multirow[t]{2}{*}{ Features } & \multicolumn{2}{|c|}{ Patients } & \multirow{2}{*}{$\begin{array}{l}\text { MRT } \\
\text { weeks }\end{array}$} \\
\hline & & $\mathrm{n}$ & $\%$ & \\
\hline \multirow{4}{*}{$\begin{array}{l}\text { Arrest of } \\
\text { progression }\end{array}$} & 1st week & 11 & 27 & 2.8 \\
\hline & 2nd week & 11 & 27 & 3.6 \\
\hline & 3rd week & 10 & 24 & 4.9 \\
\hline & 4th week & 9 & 22 & 6.9 \\
\hline \multirow{3}{*}{$\begin{array}{l}\text { Plateau } \\
\text { duration }\end{array}$} & 1 week & 34 & 83 & 4.1 \\
\hline & 2 weeks & 3 & 7 & 6.8 \\
\hline & $>2$ weeks & 2 & 5 & 8.0 \\
\hline \multirow[t]{7}{*}{ Improvement } & In 2 nd week & 2 & 5 & 2 \\
\hline & In $3 r d$ week & 15 & 37 & 3 \\
\hline & In 4 th week & 6 & 15 & 4 \\
\hline & In 5 th week & 10 & 24 & 5 \\
\hline & In 6th week & 3 & 7 & 6 \\
\hline & In 7 th week & 1 & 2 & 7 \\
\hline & In 8th week & 4 & 10 & 8 \\
\hline \multirow[t]{4}{*}{ Treatment } & No specific treatment & 2 & 5 & 4.5 \\
\hline & One course of IV IG & 30 & 77 & 3.8 \\
\hline & Two courses of IV IG & 4 & 10 & 6.0 \\
\hline & Plasma exchange & 5 & 13 & 7.0 \\
\hline
\end{tabular}

Table 6. Evaluation of poor prognostic factors in our patients with GBS

\begin{tabular}{llll}
\hline Prognostic factors & Patients & MRT & $\mathrm{p}$ \\
\cline { 2 - 2 } & $\mathrm{n} \%$ & weeks & value
\end{tabular}

\begin{tabular}{lllll}
\hline Established factors & & & & \\
$\quad$ Age $>70$ years & 3 & 7 & 3.3 & NS \\
Ventilatory support & 7 & 17 & 6.9 & 0.005 \\
Grade 6 disability in <4 days & 7 & 17 & 6.1 & 0.001 \\
Plateau duration $>14$ days & 6 & 15 & 7.0 & 0.001 \\
CMAP of median nerve $<1 \mathrm{mV}$ & 4 & 10 & 6.0 & 0.05 \\
\hline Proposed factors & & & & \\
$\quad$ Proximal weakness in UL & 7 & 17 & 6.0 & 0.005 \\
Distal weakness in LL & 4 & 10 & 7.8 & 0.001 \\
Autonomic disturbance & 5 & 12 & 6.2 & 0.025 \\
Axonal NCS & 6 & 15 & 6.0 & 0.001 \\
\hline
\end{tabular}

There was no significant difference in the MRT with prior illness, whatever the pattern of DTR on admission and presence or absence of sensory loss. Similarly, the admission and initiation of treatment within the first 3 weeks of illness did not alter the recovery pattern. MFS and older patients had an early recovery (MRT 3.3 weeks). 
The MRT for each subgroup of patients are shown in tables 2-6.

Patients with predominant distal weakness in the LL, proximal weakness in the UL, autonomic disturbance and axonal type of GBS had a poor outcome (table 6).

\section{Discussion}

GBS is a disease with a worldwide distribution affecting all ages, gender and ethnic groups. Usually, the incidence of GBS increases with age and is more common in persons 60 years or older with a male to female ratio of 1.6:1 compared to $2.7: 1$ in this study. The higher male to female ratio and the predominance of GBS cases in the middle-aged population of this study are probably a reflection of the fact that of the 41 cases, 20 were non-Kuwaitis (table 1). Generally, the non-Kuwaiti population predominantly consists of young males. For Kuwaitis, the male to female ratio was $1.8: 1$ and higher incidence in elderly as in other studies [4-10]. In an earlier study of childhood GBS in Kuwait, girls were reported to be affected more than boys [11].

GBS is a nonseasonal disease $[9,12]$ but seasonal clustering has been reported during summer in Northern China [13], spring in Taiwan [14] and winter and spring (September to March) in the Arabian Gulf region $[8,11]$ and in the present study during the winter months of November to March.

The incidence of MFS in this study was similar to that observed in the Western hemisphere [15] whereas in Taiwan [14] and Japan [16] the incidence was 19 and 25\%, respectively. The incidence of AMAN in our population is the same as that in Western countries in contrast to an incidence of 15-20\% in Japan, 40\% in Latin America and $60-70 \%$ in Northern China [1]. Western studies indicate a poor recovery for AMSAN and a faster recovery for AMAN [1,17]. Kuwabara et al. [18] reported a variable pattern of recovery (both fast and slow recovery) for AMAN. Both AMSAN and the axonal type showed a delayed recovery pattern in our study. Our patients with predominant distal weakness in LL and proximal weakness in UL had delayed recovery. This type of muscle weakness and recovery pattern were not reported in most of the other studies.

Bulbar weakness and dysautonomia were considered poor prognostic signs in a Spanish study [10] whereas they were not relevant in a Taiwanese study [14]. We observed that the development of bulbar weakness was a bad prognostic sign as these patients went on to develop autonom- ic disturbance and respiratory failure needing prolonged ventilatory support. The 7 patients who required ventilatory support and the 5 patients who had a combination of urinary retention and labile hypertension had a prolonged course of their illness.

Most of the studies report autonomic disturbance in $66 \%$ and ventilatory support in $30 \%$ of GBS patients [5, $9,10,19]$. The incidence of autonomic disturbance $(22 \%)$ and requirement for ventilatory support (17\%) was much lower in our patients. Though GBS is a monophasic illness, there are reports of acute and long-term relapses in several studies $[6,9,19,20]$ but we did not observe any acute relapse. Mortality in GBS has decreased from 33 to $5 \%$ after the introduction of positive pressure ventilatory support and advanced intensive care management $[5,9$, $21]$. No deaths were recorded in our study most probably due to the early initiation of treatment. Over the years, treatment of GBS moved from symptomatic to specific immunomodulatory therapy. PE and IV IG are of equal benefit and cost effectiveness [22]. We chose IV IG as initial therapy because of its ease of administration. Several controlled clinical trials have shown that both PE and IV IG shorten the time to recovery when used in the early stages of the neuropathy [7]. In our study, IV IG was effective up to 3 weeks after the onset of illness.

There are numerous studies about long-term prognostic pointers in GBS [2, 5, 8-10, 18, 22-24]. Although we concur with most of the commonly mentioned poor prognostic factors, they do not help in the early evaluation (within 2 weeks) of those patients who are not qualified for treatment at the outset. Hence a need exists for having clinical and electrophysiological pointers to institute early immunomodulatory therapy for the patients with less than grade 2 disability even when the weakness is still in the progressive phase. In some patients there may be late progression after 2 weeks and a favorable outcome will be denied to them if the treatment is delayed. The patients with predominant distal weakness in the LL, proximal weakness in the UL, autonomic disturbance (both hypertension and urinary incontinence together) and those with an axonal type tend to have a delayed recovery. We recommend that patients with any of these factors be given immunomodulatory therapy irrespective of other clinical factors. Since our study population was small, studies with a larger number of patients are needed before making these factors a universal guide to early initiation of treatment. 


\section{Conclusion}

Our data show that recovery is delayed in GBS patients with predominant distal weakness in the LL, proximal weakness in the UL, autonomic disturbance (both hypertension and urinary incontinence together) and those with an axonal type in the NCS. Hence, patients with any of these features should be given immunotherapy early in the course of the disease.

\section{References}

$\checkmark 1$ Asbury AK: New concepts of Guillain-Barré syndrome. J Child Neurol 2000;15:183-191.

$>2$ Mc Khann GM: Guillain-Barré syndrome clinical and therapeutic observations. Ann Neurol 1990;27(suppl):S13-S16.

$\checkmark 3$ Asbury AK, Cornblath DR: Assessment of current diagnostic criteria for Guillain-Barré syndrome. Ann Neurol 1990;27(suppl):S21-S24.

$\checkmark 4$ Ammache Z, Afifi AK, Brown CK, Kimura J: Childhood Guillain-Barré syndrome: clinical and electrophysiologic features predictive of outcome. J Child Neurol 2001;16:477-483.

5 Albers JW, Kelly JJ: Acquired inflammatory demyelinating polyneuropathies: clinical and electrodiagnostic features. Muscle Nerve 1989; 12:435-451.

6 The Italian Guillain-Barré Study Group: The prognosis and main prognostic indicators of Guillain-Barré syndrome. A multicentre prospective study of 297 patients. Brain 1996;119: 2053-2061.

7 Winer JB: Guillain-Barré syndrome. J Clin Pathol 2001;54:381-385.

-8 Bahou YG, Biary N, al Deeb S: Guillain-Barré syndrome: a series observed at Riyadh Armed Forces Hospital January 1984-January 1994. J Neurol 1996;243:147-152.

9 Bosch EP, Smith BE: Acute inflammatory demyelinating polyradiculoneuropathy; in Bradley WG: Neurology in Clinical Practice, ed 4. Philadelphia, Butterworth, Heinemann, 2004, pp 2336-2345.

$>10$ Seneviratne U: Guillain-Barré syndrome. Postgrad Med J 2000;76:774-782.
11 Ismail EAR, Shabani IS, Badawi M, Sanaa H, Madi S, Al-Tawari A, Nadi H, Zaki M, AlSaleh Q: An epidemiological, clinical, and therapeutic study of childhood Guillain-Barré syndrome in Kuwait: is it related to the oral polio vaccine? J Child Neurol 1998;134:488-492.

12 Sedano MJ, Calleja J, Canga E, Berciano J: Guillain-Barré syndrome in Cantabria, Spain. An epidemiological and clinical study. Acta Neurol Scand 1994;89:287-292.

13 McKhann GM, Cornblath DR, Griffin JW, Ho TW, Li CY, Jiang Z, Wu HS, Zhaori G, Liu Y, Jou LP, Gao CY, Mao JY, Blaster MJ, Mishu B, Asbury AK: Acute motor axonal neuropathy: A frequent cause of acute flaccid paralysis in China. Ann Neurol 1993;33:333-342.

14 Lyu RK, Tang LM, Cheng SY, Hsu W, Chen $\mathrm{S}$ : Guillain-Barré syndrome in Taiwan: a clinical study of 167 patients. J Neurol Neurosurg Psychiatry 1997;63:494-500.

$>15$ Ropper AH: The Guillain-Barré syndrome. N Engl J Med 1992;326:1130-1136.

$>16$ Mori M, Kuwabara S, Fukutake T, Yuki N, Hattori T: Clinical features and prognosis of Miller Fisher syndrome. Neurology 2001;56: 1104-1106.

$\checkmark 17$ Ho TW, Li CY, Cornblath DR, Gao CY, Asbury AK, Griffin JW, McKhann GM: Patterns of recovery in the Guillain-Barré syndromes. Neurol 1997;48:695-700.
8 Kuwabara S, Mori M, Ogawara K, Hattori T, Yuki N: Indicators of rapid clinical recovery in Guillain-Barré syndrome. J Neurol Neurosurg Psychiatry 2001;70:560-562.

19 Barohn RJ, Saperstein DS: Guillain-Barré syndrome and chronic Inflammatory demyelinating polyneuropathy. Semin Neurol 1998;18: 49-54.

20 Koul R, Chacko A, Ahamed R, Varghese T, Javed H, Al-Lamki Z: Ten year prospective study (clinical spectrum) of childhood Guillain-Barré syndrome in the Arabian Peninsula: comparison of outcome in patients in the preand post-intravenous immunoglobulin eras. $\mathrm{J}$ Child Neurol 2003;18:767-771.

-21 Kleyweg RP, Van Der Meche FGA, Loonen MCB, De Jonge J, Nip BK: The natural history of the Guillain-Barré syndrome in 18 children and 50 adults. J Neurol Neurosurg Psychiatry 1989;52:853-856.

22 Plasma Exchange/Sandoglobulin GuillainBarré Syndrome Trial Group. Randomized trial of plasma exchange, intravenous immunoglobulin, and combined treatments in Guillain-Barré syndrome. Lancet 1997;349:225230.

23 Cornblath DR: Electrophysiology in GuillainBarré Syndrome. Ann Neurol 1990;27(suppl): S17-S20.

24 Hiraga A, Mori M, Ogawara K, Hattori T, Kuwabara S: Difference in patterns of progression in demyelinating and axonal Guillain-Barré syndromes. Neurol 2003;61:471-474. 